\title{
Lean Healthcare applied toward turning a Pharmacy Service Patient Centered
}

\author{
Bruna Stella Zanotto ${ }^{\mathrm{a}, \mathrm{b}^{*}}$, Gabriela C. Bittencourt ${ }^{\mathrm{c}}$, Caroline Tortato ${ }^{\mathrm{d}}$, Jacqueline K. \\ Martinbiancho $^{\mathrm{d}}$, Janaína R. Chagas ${ }^{\mathrm{d}}$, Karen Brasil Ruschel ${ }^{\mathrm{a}}$, Ana Paula Etges ${ }^{\mathrm{a}, \mathrm{c}}$, Carisi \\ A. Polanczyk ${ }^{\mathrm{a}, \mathrm{b}}$
}

aNational Health Technology Assessment Institute, CNPq, Hospital de Clínicas de Porto Alegre, Porto Alegre, RS, Brazil.

${ }^{b}$ Federal University of Rio Grande do Sul, Porto Alegre, RS, Brazil.

${ }^{\mathrm{c} S}$ Shool of Technology, Pontificia Universidade Católica do Rio Grande do Sul, Porto Alegre, RS, Brazil ${ }^{\mathrm{d} P h a r m a c y}$ Service, Hospital de Clínicas de Porto Alegre, Porto Alegre, RS, Brazil.

Histórico do Artigo

Recebido em:

09/01/2020

Aceito em:

23/03/2020

Keywords:

Lean healthcare;

clinical pharmacy;

value-based health care; hospital pharmacy; patientcentered care

\begin{abstract}
Pharmaceutical service optimization requires a comprehensive understanding of resource usage. The aim of the study is to analyze how Lean Healthcare principles can contribute toward turning a pharmacy service patient-centered and value oriented. Understand how clinical pharmacists' resources are effectively used by patients in an academic hospital using lean tools, such as value stream mapping and activity designation matrix, determine the amount of time each professional is involved in specific activities, and identify activities that add value. The data were mainly obtained through interviews with professionals, time-motion observational studies, chronoanalysis and meetings with the head of the unit. A process flow map is designed for clinical pharmacy services, and it considers the relationship between the activities and their added value base. An exploration of the map shows that the activity "clinical rounds" is the most time consuming (27\%) and not necessarily considered value-added by both parties (pharmacists staff and head of service). It is notable the opportunity the service has to prioritize the high-risk patients and to make a good time management; furthermore, activities that are of high value to patients are being performed and monitored by interns. The role of pharmacists should evolve from now on to be congruent with the new realities of healthcare. When value is questioned, we are encouraged to reflect on the activities engaged in by professional pharmacists in a clinical/surgical unit of a hospital. Through these tools, we could infer how the system is engaged and how it can be transformed toward added value.
\end{abstract}

Lean Healthcare aplicado para tornar um serviço de farmácia clínica centrado no paciente

RESUMO

A otimização do serviço farmacêutico requer uma compreensão detalhada do uso de recursos. O estudo tem como objetivo analisar como os princípios de Lean Healthcare podem contribuir para tornar um serviço de farmácia clínica centrado no paciente e orientado a valor. Entender como os recursos dos farmacêuticos clínicos são efetivamente usados pelos pacientes em um hospital acadêmico usando ferramentas lean, como mapeamento de fluxo de valor e matriz de designação de atividades, determinar a quantidade de tempo que o profissional está envolvido em atividades específicas e identificar atividades que agregam valor. Os dados foram obtidos principalmente por meio de entrevistas com profissionais, estudos observacionais de tempo de movimento, cronoanálise e reuniões com a chefe da unidade. Um mapa do fluxo do processo é projetado para serviços de farmácia clínica e considera a relação entre as atividades e sua base de valor agregado. Uma exploração do mapa mostra que a atividade "rounds multidisciplinares" é a que consome mais tempo (27\%) e não é necessariamente considerada uma atividade que agrega valor por ambas as partes (time de farmacêuticos clínicos e chefe de serviço). É notável a oportunidade que o serviço tem para priorizar os pacientes de alto risco e fazer um bom gerenciamento de tempo; além disso, atividades de alto valor para os pacientes estão sendo realizadas e monitoradas por estagiários. O papel dos farmacêuticos deve evoluir a partir de agora para ser congruente com as novas realidades da saúde. Quando o valor é questionado, somos incentivados a refletir sobre as atividades realizadas por farmacêuticos profissionais em uma unidade clínica / cirúrgica de um hospital. Por meio dessas ferramentas, podemos inferir como o sistema está envolvido e como ele pode ser transformado em valor agregado.

\footnotetext{
*Corresponding author: cpolnaczyk@ hcpa.edu.br (Polanczyk, C.A)
} 


\section{Introduction}

The system we have today emerges out of a legacy that reflects different circumstances (1) when technology, mobility and the value concept were distinct. The legacy system, therefore, is not aligned with the value that can be delivered. Clinical duties should be delivered based on the health needs perceived by the user and should be performed by professionals (2). In an institution characterized by high managerial complexity, such as hospitals (3), one of the services with the greatest social importance is provided by the clinical pharmacy.

As it has evolved from a dispensary-based function to a patient-based function (4), the clinical pharmacist service considers multiple factors, such as the delivery of clinical care, which requires knowledge of semiology and therapeutics, participation in case discussions with multidisciplinary teams, and transmission of opinions about the patient and the treatment, and it must also focus on issues of adherence to treatment and health outcomes (5). Healthcare services with workflow issues, such as inefficient drug dispensing process or delayed evaluation of inpatient clinical records, often leads with difficulties assessing care delivery capacity and overload professionals (6-8). In terms of that, to meet an institution's natural changes overtime, such as increasing capacity or reallocating resources towards value, a deep understanding of the associated human resources and how they have been used in the patient care process is necessary.

According to Batalden and Davidoff (2007) (9), quality improvement can be defined as making changes that will lead to better patient outcomes, better system performance and better professional development. Thus, a current trend of health management these days seeks for a method that contributes to achieve a patient resource usage understanding and value delivered. A promising approach often employed by leading healthcare institutions is Lean Healthcare (10). Most of the published examples of Lean Healthcare highlight the use of specific activities, such as an activity designation matrix and value stream mapping, to achieve short-term improvements (11), and they also highlight the importance of this method for increasing the internal knowledge of the processes $(12,13)$. Creating a detailed representation of the process facilitates a better understanding of the current state of the service (10) and can identify opportunities for improvement.

The aim of the study is to analyze how Lean Healthcare principles and tools can contribute toward turning a pharmacy service patient-centered and value oriented.

\section{Materials and Methods}

\section{Lean principles and tools usage in the healthcare field}

Lean management is a set of principles that constitute a mindset geared toward constantly improving processes $(14,15)$. Womack and Jones (15) define it in five basic principles: specify value, identify the value stream, reiterate value into the workflow, let customers pull value, and start pursuing perfection. They are mutually reinforcing and interact to each other in a virtuous cycle $(10,15,16)$. Principles evolves from a diagnostic character to set up improvement environment.

Further, Lean activities are a set of management tools, or techniques that can be directly observed and are prescribed to improve the workplace (16). They can have both character of assessment and work as analytic tools to identify areas of possible improvement, or character of improvement and respond as a set up for new practices. Lean tools are helpful in diagnosing the current scenario and they compose the advance to Lean principles progress. 
Among the literature on the applications of Lean Healthcare, studies in particular analyze how the process of Lean Healthcare was implemented in both national $(17,18)$ and international $(14,19,20)$ scenarios. The results of these studies and in many other reviews $(4,16,19,21,22)$ showed the processes of implementing Lean Healthcare had many similarities based on an understanding of the processes involved in flows of patients, materials or information. The most common tools were visual management, spaghetti map, time and motion studies, value stream mapping (VSM), Kaizen principles, standardization, $(17,18,23)$ process mapping $(11,24)$ and semi-structured interviews, documentary analyses and nonsystematic observations (23).

In the pharmacy area, the VSM and unfolding tools stand out. This practice is usually cited as one of the first initiatives in the improvement implementation process, however as Borges et al. (25) discusses, it is common the usage of value streams in the healthcare field as process flows or even a work operation (26) which may include materials, patients, medicines, equipment, services, among others.

Sullivan et al. (27), for example, showed that after implementation of the patient flow map and its resources, the flow lead time decreased by 20 minutes in the pharmacy of an oncology hospital in the USA. Also, the time and motion studies described by Fisher et al. (12) sought to determine the time allocation of the pharmacist in a free clinic dispensary.

\section{Study scenario}

The study attempts to detail the process of developing a value-based health care culture by showing the current scenario of the clinical pharmacy service in which professionals work and use their time and how the patients benefit from such actions.

The evaluated clinical pharmacy service is situated in a public teaching hospital in Southern Brazil. The clinical pharmacy services an average of 1652 patients per month according to their data, and it also relies on the workforce of 11 pharmacists, resident students, undergraduate interns attached to the hospital and undergraduate fellowships linked with the university and involved in pharmacy clinical hospital experience projects.

\section{Lean assessment activities}

The research was divided in three main steps: 1) the application of Lean tools - patient flow map and activity designation matrix, 2) time data collection, 3) the identification of value-added and non-value-added steps through interviews with the professionals and with the manager of the Clinical Pharmacy Service

Firstly, we accessed the process flow map as a diagrammatic representation of the patient's journey through the system, and it identifies the stages the individual passes through during hospitalization which allows the team to more clearly identify the current state of a complex system and provides guidelines for improvement (28). Additionally, since it is already expected that specific patient situations can trigger and lead to specific tasks, and these triggers are defined as "flags"(29-32). Once the process flow map is done, an activity designation matrix is included in this context to define the roles (the responsible, the authority, the consulted and the informed) of each human resource in the execution of the activities (28). Also called a Responsibility Assignment Matrix (RAM), it provides a way to plan, organize and coordinate work that consists of assigning different degrees of responsibility to the members of an organization for each activity that is undertaken (33). 
Secondly, despite the time data collection being a complementary methodology to the Lean tools applied, the results were used to identify the main activities that consume the largest proportion of a pharmacist's time and the individual performing these activities $(12,34)$. And finally, value-added activities are defined as any activity that add value to the customer, and they are considered by the customer to provide a direct benefit $(15,35)$. With the purpose to distinguish value and non-value added activities, interviews were conducted with pharmacists workforce and this step also enlisted help of the head of the service to elucidate what is known about the role of the clinical pharmacist on patient centered care.

\section{Data collection}

The collection was performed with a stopwatch every working day over a month for approximately 3 hours per day, and the morning and afternoon shifts were alternated.

Moreover, the results were used to measure the various times associated with the process, such as the times required for the execution of each activity (unit time). Only five pharmacists and one trainee were observed over the course of their working periods for data collection.

For the value-based activities step, a simplified and objective form of content analysis was conducted based on a total of 11 transcribed interviews, it aimed to consider unambiguous characteristics of the text such as words frequencies and justification of answer's choice. Participants provided informed consent previously foreseen and approved by the Ethics Committee. The majority of answers of value or not value activity was the definitory for categorizing an activity

\section{Data analysis}

The study attempts to detail the process of developing a value-based health care culture by showing the current scenario of the clinical pharmacy service in which professionals work and use their time and how the patients benefit from such actions. The cross analysis of activities time and resources consume versus the activities value allow us to interpret the resource measurement utilization as a method of measuring care delivery. Moreover, the results were used to measure the various times associated with the process, such as the times required for the execution of each activity (unit time).

\section{Ethics}

This study was first approved by the Hospital Ethics Committee with the Certificate of Presentation for Ethical Appreciation (CAAE) 91676518.6.0000.5327

\section{Results}

\section{Process flow map}

The current activities and its description are available in Table 1. The extra activity researchers defined as "other" were activities that the pharmacists engaged in frequently and could not be reported in the process map because they were not representative of a given patient's journey. The class of activities (other) was divided into administrative, research, education and traveling. 


\section{Time data collection}

The results from the chronoanalysis with the relative percentages time concentrated in each activity by the pharmacists are demonstrated in Table 2 .

Clinical rounds, medical record evaluation stands out by its representative times, respectively, $27 \%$ and $25 \%$ of total measured time. Otherwise few activities seem to be frequent but not time costly such as, patient follow-up record update and intervention. The activity of "others" was measured as it occurred during collection but was not recorded by its subcategories.

Table 1 - Clinical pharmacist activities identified and its description.

\section{ACTIVITIES}

\section{Patient's follow up record elaboration}

\section{Patient's follow up record update}

\section{Prescription evaluation}

\section{Clinical rounds}

\section{Medical record evaluation}

\section{Intervention}

\section{Medical record evolution}

\section{Pharmacist record's} registration

\section{Conciliation}

10. Validation

\section{Discharge orientation}

\section{Consultancy}

13. Pharmacovigilance notification

14 A. Other- administrative 14 B. Other- research and education

14 C. Other- traveling

\section{DESCRIPTION}

Construction of the follow-up card prepared for patients who are part of the internal medicine team. This record contains personal data of the patient, patient history, history of disease, reason for interaction and current clinical management

Update of the patient's follow up record according to the clinical conducts happened.

Evaluation of the medical prescription for each patient: its posology, dose, pharmaceutical form and indication of the medication

Multidisciplinary ward which is discussed the clinical management and updates about a patient who is part of the internal medicine team.

Evaluation of the medical record of each patient: its registration in which the pharmacist obtains all the information inherent to the patient, from examines, all previous hospitalizations of the patient, comorbidities, all the activities records of the of the other health professionals.

Any mediation or prescription modification done by the pharmacist. This activity can be made through system, telephone or personal.

Activity regarding the register of any pharmacist activity performed in benefit of the patient on the medical record.

Unit internal assistance control indicator.

Drug conciliation is an activity described of obtaining a complete and accurate list of the medicines that each patient already uses and later comparison with the prescription in all the transitions of care (admission, hospital discharge or transfer between units of hospitalization).

Pharmacist authenticattion of the medicines brought by the patient by checking the origin, expiration date, packaging integrity, appearance and identification of the product.

Pharmacists ending guidance to increase the capacity for self-care in the transition from dependent patient to autonomous individual, to strengthen adherence to the proposed treatment, to improve communication between the hospital and the care provided in primary care services to reduce the discrepancies between pharmacotherapeutic regimens before and after hospitalization.

Consulting or advisory asked by other health professional.

Report of any adverse event to medication. An important tool in obtaining pharmacovigilance and safety data.

Administrative duties to the sector.

Research and education of new professionals, trainees, fellows, students since it is an academic hospital.

Displacement within the hospital to fulfill daily activities. 
Table 2 - Task categories used and total time investment during data collection.

\begin{tabular}{|c|c|c|c|c|}
\hline Tasks & $\begin{array}{c}\text { Percentage of } \\
\text { total time }\end{array}$ & $\begin{array}{c}\text { Absolute } \\
\text { hours (hr) }\end{array}$ & Frequency & $\begin{array}{c}\text { Unit time } \\
(\mathrm{min})^{\mathbf{b}}\end{array}$ \\
\hline $\begin{array}{l}\text { 1. Patient follow-up record } \\
\text { elaboration }\end{array}$ & $3 \%$ & 1.73 & 7 & $14(9-18)^{\mathrm{a}}$ \\
\hline $\begin{array}{l}\text { 2. Patient follow-up record } \\
\text { update }\end{array}$ & $6 \%$ & 3.40 & 53 & $3(1.8-5)^{\mathrm{a}}$ \\
\hline 3. Prescription evaluation & $2 \%$ & 0.98 & 32 & $1.5(0.60-2)^{\mathrm{a}}$ \\
\hline 4. Clinical rounds & $27 \%$ & 16.37 & 13 & $87(24-125)^{\mathrm{a}}$ \\
\hline 5. Medical record evaluation & $25 \%$ & 14.90 & 38 & $3.7(2.8-7.6)^{\mathrm{a}}$ \\
\hline 6. Intervention & $2 \%$ & 0.98 & 24 & $2(1-3.8)^{\mathrm{a}}$ \\
\hline 7. Medical record evolution & $2 \%$ & 1.18 & 14 & $4.5(2.7-7.4)^{\mathrm{a}}$ \\
\hline $\begin{array}{l}\text { 8. Pharmacist record's } \\
\text { registration }\end{array}$ & $2 \%$ & 1.05 & 53 & $0.5(0.3-1)^{\mathrm{a}}$ \\
\hline 9. Medication reconciliation & $2 \%$ & 1.12 & 11 & $4.7(3.8-6.7)^{\mathrm{a}}$ \\
\hline 10. Medication validation & $1 \%$ & 0.54 & 8 & $2.8(1.6-6.6)^{\mathrm{a}}$ \\
\hline 11. Discharge orientation & $5 \%$ & 2.87 & 23 & $6.5(2-12.3)^{\mathrm{a}}$ \\
\hline 12. Consultancy & $2 \%$ & 1.08 & 8 & $5.3(1.4-16.3)^{\mathrm{a}}$ \\
\hline $\begin{array}{l}\text { 13. Pharmacovigilance } \\
\text { notification }\end{array}$ & $0.31 \%$ & 0.19 & 3 & $3(3-5.4)^{\mathrm{b}}$ \\
\hline 14. Others & $23 \%$ & 13.79 & 90 & $1.95(1-5.5)^{\mathrm{a}}$ \\
\hline
\end{tabular}

aReported as the median and 25th-75th percentile range.

${ }^{\mathrm{b}}$ Reported as the median and range

\section{Value-added and non-value-added activities}

An assessment of the current flow map demonstrated that seven of the formal activities performed by the pharmacist were considered value-added processes by mutual consent (of the pharmacist staff and the head of service). Those activities were prescription evaluation, medical record evaluation, intervention, medical record evolution, medication reconciliation, medication validation and discharge orientation.

There were two activities with conflicting assessments between the head of the service and the professionals. The activities that the professionals considered value-added and that the manager did not were "clinical rounds" and "research and education" (stratified by "other activities").

\section{Activity designation matrix}

The activity designation matrix is presented in Table 3 and shows how the activity is related to the five levels of workforce in the clinical pharmacy service.

Table 3 - Activity Designation Matrix.

\begin{tabular}{|c|c|c|c|c|c|}
\hline & & & Resource & & \\
\hline Activities & $\begin{array}{c}\text { Pharmacy } \\
\text { Fellow } \\
\text { Student } \\
\end{array}$ & Trainees & Resident & $\begin{array}{l}\text { Pharmacy } \\
\text { Professional }\end{array}$ & $\begin{array}{l}\text { Head of } \\
\text { the } \\
\text { Service }\end{array}$ \\
\hline $\begin{array}{l}\text { 1. Patient follow-up record } \\
\text { elaboration }\end{array}$ & $\mathrm{P}$ & & $\mathrm{P} / \mathrm{R} / \mathrm{I}$ & $\mathrm{P} / \mathrm{R} / \mathrm{I} / \mathrm{C}$ & \\
\hline $\begin{array}{l}\text { 2. Patient follow-up record } \\
\text { update }\end{array}$ & $P$ & & $\mathrm{P} / \mathrm{R} / \mathrm{I}$ & $\mathrm{P} / \mathrm{R} / \mathrm{I} / \mathrm{C}$ & \\
\hline 3. Prescription evaluation & & & $\mathrm{P} / \mathrm{R}$ & $\mathrm{P} / \mathrm{R}$ & \\
\hline 4. Clinical rounds & I & & $\mathrm{P} / \mathrm{I}$ & $\mathrm{P} / \mathrm{I}$ & $\begin{array}{l}\mathrm{P} / \mathrm{R} / \mathrm{I} / \\
\mathrm{C}\end{array}$ \\
\hline 5. Medical record evaluation & $\mathrm{P} / \mathrm{I}$ & $\mathrm{P} / \mathrm{I}$ & $\mathrm{P} / \mathrm{R} / \mathrm{I}$ & $\mathrm{P} / \mathrm{R} / \mathrm{I} / \mathrm{C}$ & $\mathrm{P} / \mathrm{R}$ \\
\hline 6. Intervention & & & $\mathrm{P} / \mathrm{R}$ & $\mathrm{P} / \mathrm{R}$ & $\mathrm{P} / \mathrm{R}$ \\
\hline 7. Medical record evolution & & & $\mathrm{P}$ & $\mathrm{P} / \mathrm{R}$ & $\mathrm{C}$ \\
\hline
\end{tabular}


Continuação

\begin{tabular}{llllll}
\hline Activities & $\begin{array}{c}\text { Pharmacy } \\
\text { Fellow } \\
\text { Student }\end{array}$ & Trainees & Resident & $\begin{array}{c}\text { Pharmacy } \\
\text { Professional }\end{array}$ & $\begin{array}{c}\text { Head of } \\
\text { the } \\
\text { Service }\end{array}$ \\
\hline $\begin{array}{l}\text { 8. Pharmacist record's } \\
\text { registration }\end{array}$ & $\mathrm{P}$ & & $\mathrm{P} / \mathrm{R}$ & $\mathrm{P} / \mathrm{R}$ & $\mathrm{C}$ \\
9. Medication reconciliation & $\mathrm{P}$ & $\mathrm{P}$ & $\mathrm{P} / \mathrm{R}$ & $\mathrm{P} / \mathrm{R} / \mathrm{I} / \mathrm{C}$ & \\
10. Medication validation & $\mathrm{P}$ & $\mathrm{P}$ & $\mathrm{P} / \mathrm{R} / \mathrm{I}$ & $\mathrm{P} / \mathrm{R} / \mathrm{C}$ & \\
11. Discharge orientation & $\mathrm{I}$ & $\mathrm{I}$ & $\mathrm{P} / \mathrm{R} / \mathrm{I}$ & $\mathrm{P} / \mathrm{R} / \mathrm{I}$ & \\
$\begin{array}{l}\text { 12. Consultancy } \\
\text { 13. Pharmacovigilance }\end{array}$ & $\mathrm{P}$ & $\mathrm{P}$ & $\mathrm{P} / \mathrm{R}$ & $\mathrm{P} / \mathrm{I}$ & \\
notification & & & $\mathrm{P} / \mathrm{R}$ & $\mathrm{P} / \mathrm{R}$ & \\
14a. Other-administrative & & & $\mathrm{P} / \mathrm{I}$ & & $\mathrm{P} / \mathrm{R} / \mathrm{C}$ \\
14b. Other-research and & & & $\mathrm{P} / \mathrm{I}$ & $\mathrm{P} / \mathrm{R}$ & $\mathrm{P} / \mathrm{R} / \mathrm{C}$ \\
$\begin{array}{l}\text { education } \\
\text { 14c. Other-traveling }\end{array}$ & $\mathrm{P}$ & $\mathrm{P}$ & $\mathrm{P}$ & $\mathrm{P}$ & $\mathrm{P}$ \\
\hline${ }_{\mathrm{a}} \mathrm{P}=$ Performer, R=Responsible, I=Information User, C=Controls & & & \\
\hline
\end{tabular}

\section{Discussion}

The identification of how pharmacists' activities add value to patient-centered care is a core issue in the healthcare field, and it is implicit in the way we organize the delivery of care. Since Lean is a methodology that refers to improvements in quality, organization and focus on the activity $(21,33)$, we sought to visualize the results of these two great concepts together. The results of this study provide insights into the interactions of Lean Healthcare, value-based health care and pharmacist centered on patients, and they can be used by healthcare organizations.

However, the multidisciplinary component of this activity can be further expanded, such as if it involves a session with medical students, which is very focused on diagnostic skills, activities in the medical clinic and the proactivity of students. The involvement of the pharmacist is undoubtedly important, although the manner in which this involvement takes place is questionable, and there is room for change. Similar scenarios are found in the literature, for example, a considerable proportion of a nurse's "care time" is taken up with practical administrative tasks $(8,36)$ including undertaking ward rounds. Therefore, our results indicate that allocating clinical time toward rounds is not justified. Additionally, if clinical rounds were a more clearly defined task, other professionals would be able to optimize their interventions so that everyone could be aware of any possible updates at the beginning of the meeting. A solution would be for the hospital itself to draw up a workplace standard outlining how the multidisciplinary rounds should be organized, which has been suggested in previous studies, such as Moroney (37), Fiddler (36) and Burger (38). Such a standard could increase the effectiveness of the activity and maintain the aim of continuum education.

On the one hand, we realize the importance of task supervision and the need for conferences. From our data, we can see that activities with high added value are mostly engaged in by residents or interns. The activity designation matrix concept (30) highlights the merit of having external oversight of error-prone tasks, such as those involving manual work. Hence, the performer should not be the same individual who controls or is responsible for the task. When external performance measures are considered, this method significantly contributes to enhancing internal project performance (28). In this way, we stop measuring the process and start measuring outcomes (1). John et al. (39) stressed the importance of orientated standard work and 
transparency when incorporating Lean methodology into a pharmacy residency programs. The same study also implemented one-on-one resident progression meetings with preceptors. These meetings generally do not exceed 15 minutes and solved the problem of variability because they focused on the resident's strengths and areas of improvement at the rotation midpoint (39). The use of RAM as a method of applying the standardization of Lean tools ensures the reduction in the variability of the process because the product is always performed in the same way (18) or by the same person.

Given the diversity of morbidities that affect patients, variations in the time required to perform pharmaceutical tasks also have a great impact because they affect the ability to prioritize high-risk patients and prevent good time management. Other authors have noted similar problems $(29,31,32)$ and highlighted the importance of creating a software-based tool to help prioritize patients. In the study by Falconer et al. (32), the average number of patients receiving medication reconciliation each month increased from 280 to 500 in the first 18 months after implementing such technology. A softwarebased tool could enable a hospital's clinical pharmacists to conduct value-added activities, such as medication reconciliation and medical records review, in a more timely and targeted manner.

Another point of discussion in Lean management are the activities that are necessary but not exclusively value-added (15). This is particularly notable in the classification of other activities, such as administrative and traveling. It is important to brought up displacement as an inherent process and can explicit the time required for some activities that are value-added. From previous studies $(14,20,36)$ it can be inferred the great concern in increase the time dedicated to value-added activities plus identified and extinguish those non-value added. The real turning point is that by the time the service format is toward patient-centered care, the tasks that are mandatory but do not necessarily add value to the patient will be less representative in front of the results achieved for the patient (15), the system then becomes sustainable.

Lean principles have provided us with a greater ability to discern pharmacist activities during analyses. Understanding the current state of affairs is key to identifying the improvements that can be made to better tailor solutions to how improvements should be made rather than to what improvements need to be made $(10,40)$. Through these tools, we could infer how the system is engaged and how it can be transformed toward added value to improve the overall quality of care (41). The current system is organized around the services provided, the tools stored and the medical staff and is focused on prioritizing the organization around patient problems and needs (1) delivering the kind of service that improves value.

The proposed changes, such as a protocol implementation for multidisciplinary ward rounds, activity supervision and patient prioritization system, can help enrich the valueadded activities in the pharmaceutical service. For any change to be successfully implemented, the perspectives of those involved in the process must be explored (36).

There are several limitations to consider. First, although time measurement was not the primary goal of this article, the period of data collection should be greater because a longer collection time would provide for more reliable average data. Second, we recognize that this methodology may cause confusion regarding the pharmacists' categorization of value-added and non-value-added tasks. In addition, our study lacks interviews from other healthcare professionals. However, the Lean methodology encourages the identification of value according to the job executor, which explains our use of the value categorizations of the pharmacists. Third, it is difficult to assess the generalizability of our findings because the results represent a specific scenario in a clinical pharmacy service. We did not intend to cover all Lean principles, here we 
proposed changes to redesign the workflow through patient-centered care, but we do encourage continuum researches to track performance among principles lean hierarchy.

\section{Conclusions}

Lean activities applied to healthcare inevitably call for the redefinition of roles and responsibilities. The role of pharmacists should evolve to be congruent with the new realities of patient-centered healthcare. For the purposes of a teaching hospital, the benefits of processes, functions and activities definition and its contribution towards value generation should be assessed. Changing the focus of pharmacists towards performing tasks that impact patient health and providing a greater resolution of actions is recommended.

\section{Acknowledgments}

Thalita S. Jacoby, chief of the Pharmacy Service in the studied hospital, is acknowledged for her constant interest in the research and the impact that could be generated. The first author was supported by a research scholarship from the National Council for Scientific and Technological Development.

\section{Conflict of Interest}

The authors have declared no potential conflicts of interest.

\section{Data availability}

Main data supporting the method used in this research has been made available in formats compatible with those proposed by the journal. In addition, the corresponding author is available for any further request.

\section{References}

1. Porter ME. What Is Value in Health Care? N Engl J Med. 2010; 363(26): 2477-81.

2. Universidade Federal de Santa Catarina. Assistência farmacêutica no Brasil: política, gestão e clínica. Florianópolis, SC: Editora UFSC; 2016. 5 p.

3. Bonato VL. Health quality management: improving support to client. O Mundo Saúde 2011; 35(5): 319-31.

4. Kaboli PJ, Hoth AB, McClimon BJ, Schnipper JL. Clinical pharmacists and inpatient medical care: a systematic review. Arch Intern Med 2006; 166(9): 955-64.

5. Hassan WE. Hospital Pharmacy. In: Hospital Pharmacy. 3rd ed. Lea \& Febiger, 1974.

6. Al-Araidah O, Momani A, Khasawneh M, Momani M. Lead-Time Reduction Utilizing Lean Tools Applied to Healthcare: The Inpatient Pharmacy at a Local Hospital: J Healthc Qual 2010; 32(1): 59-66.

7. Hintzen BL, Knoer SJ, Van Dyke CJ, Milavitz BS. Effect of lean process improvement techniques on a university hospital inpatient pharmacy. Am J Health Syst Pharm 2009; 66(22): 2042-7.

8. Gijbels M. Mental health nursing skills in an acute admission environment: perceptions of mental health nurses and other mental health professionals. J Adv Nurs 1995; 21(3): 460-5.

9. Batalden PB, Davidoff F. What is "quality improvement" and how can it transform healthcare? Qual Saf Health Care 2007; 16(1): 2-3.

10. John S. Toussaint, Leonard L. Berry. A promessa de lean na área da saúde. Mayo Clin Proc 2013; 88(1): 74-82.

11. Mazzocato P, Holden RJ, Brommels M, Aronsson H, Bäckman U, Elg M, Thor J. How does lean work in emergency care? A case study of a lean-inspired intervention at the Astrid Lindgren Children's hospital, Stockholm, Sweden. BMC Health Serv Res. 2012; 12:28.

12. Fisher AM, Ding MQ, Hochheiser H, Douglas GP. Measuring time utilization of pharmacists in the 
Birmingham Free Clinic dispensary. BMC Health Serv Res 2016; 16(1): 529.

13. Wolf L, Costantinou E, Limbaugh C, Rensing K, Gabbart P, Matt P. Fall Prevention for Inpatient Oncology Using Lean and Rapid Improvement Event Techniques. HERD Health Environ Res Des J 2013; 7(1): 85-101.

14. Sommer AC, Blumenthal EZ. Implementation of Lean and Six Sigma principles in ophthalmology for improving quality of care and patient flow. Surv Ophthalmol 2019; 64(5): 720-8.

15. Womack JP, Jones DT. Lean thinking: banish waste and create wealth in your corporation. 1 st Free Press ed., rev.updated. New York: Free Press; 2003. 396 p.

16. Rotter T, Plishka C, Lawal A, Harrison L, Sari N, Goodridge D, et al. What Is Lean Management in Health Care? Development of an Operational Definition for a Cochrane Systematic Review. Eval Health Prof 2019; 42(3): 366-90.

17. Inacio BC, Aragao JF, Bergiante JCR. Implementação da Metodologia Lean Healthcare no Brasil: um estudo bibliométrico. In João Pessoa, Brazil; 2016.

18. Ribeiro ACGC. Implementação da Filosofia Lean na Gestão dos Serviços de Saúde: o Caso dos Centros de Saúde da Região Norte. Brazil; 2013.

19. Poksinska B. The Current State of Lean Implementation in Health Care: Literature Review. Qual Manag Health Care 2010; 19(4):319-29.

20. O’Mara MS, Ramaniuk A, Graymire V, Rozzell M, Martin S. Lean methodology for performance improvement in the trauma discharge process: J Trauma Acute Care Surg 2014; 77(1): 137-42.

21. Terra JDR, Berssaneti FT. Application of lean healthcare in hospital services: a review of the literature (2007 to 2017). Production 2018; 28: e20180009.

22. Moraros J, Lemstra M, Nwankwo C. Lean interventions in healthcare: do they actually work? A systematic literature review. Int J Qual Health Care 2016; 28(2): 150-65.

23. Régis TKO, Gohr CF, Santos LC. Implementação do Lean Healthcare: experiências e lições aprendidas em hospitais brasileiros. Rev Adm Empres. 2018; 58(1): 30-43.

24. Dickson EW, Singh S, Cheung DS, Wyatt CC, Nugent AS. Application of Lean Manufacturing Techniques in the Emergency Department. J Emerg Med. 2009; 37(2): 177-82.

25. Borges GA, Tortorella G, Rossini M, Portioli-Staudacher A. Lean implementation in healthcare supply chain: a scoping review. J Health Organ Manag. 2019; 33(3): 304-22.

26. McGough P, Kline S, Simpson L. Team care approach to population health and care management. Int J Health Gov 2017; 22(2): 93-103.

27. Sullivan P, Soefje S, Reinhart D, McGeary C, Cabie ED. Using lean methodology to improve productivity in a hospital oncology pharmacy. Am J Health Syst Pharm 2014; 71(17): 1491-8.

28. Golini R, Kalchschmidt M, Landoni P. Adoption of project management practices: The impact on international development projects of non-governmental organizations. Int J Proj Manag 2015; 33(3): 650-63.

29. Hu Q, Qin Z, Zhan M, Wu B, Chen Z, Xu T. Development of a trigger tool for the detection of adverse drug events in Chinese geriatric inpatients using the Delphi method. Int J Clin Pharm 2019; 41(5): 1174-1183

30. Martinbiacho JK, Zuckermann JDP. Mahmud S, dos Santos L, Jacoby T, da Silva D, Vinhas M. Development of Risk Score to Hospitalized Patients for Clinical Pharmacy Rationalization in a High Complexity Hospital. Lat Am J Pharm 2011; 30(7): 1342-7.

31. Hickson RP, Steinke DT, Skitterall C, Williams SD. Evaluation of a pharmaceutical assessment screening tool to measure patient acuity and prioritise pharmaceutical care in a UK hospital. Eur J Hosp Pharm 2017;24(2): 74-9.

32. Falconer N, Nand S, Liow D, Jackson A, Seddon M. Development of an electronic patient prioritization tool for clinical pharmacist interventions. Am J Health Syst Pharm 2014;71(4): 311-20.

33. Lawal AK, Rotter T, Kinsman L, Sari N, Harrison L, Jeffery C, et al. Lean management in health care: definition, concepts, methodology and effects reported (systematic review protocol). Syst Rev 2014; 3(1): 103.

34. Lopetegui M, Yen P-Y, Lai A, Jeffries J, Embi P, Payne P. Time motion studies in healthcare: What are we talking about? J Biomed Infor 2014; 49:292-9.

35. Dowse R. Reflecting on patient-centred care in pharmacy through an illness narrative. Int $\mathbf{J}$ Clin Pharm. 2015; 37(4): 551-4.

36. Fiddler M, Borglin G, Galloway A, Jackson C, McGowan L, Lovell K. Once-a-week psychiatric ward round or daily inpatient team meeting? A multidisciplinary mental health team's experience of new ways of working. Int J Ment Health Nurs 2010, 19(2): 119-27.

37. Moroney N, Knowles C. Innovation and teamwork: introducing multidisciplinary team ward rounds. Nurs Manag (Harrow) 2006; 13 (1): 28-31.

38. Burger CD. Multi-Disciplinary Rounds: A Method to Improve Quality and Safety of Critically Ill 
Patients. Northeast Fla Med 2007; 58(3): 16-19.

39. John N, Snider H, Edgerton L, Whalin L. Incorporation of lean methodology into pharmacy residency programs. Am J Health Syst Pharm 2017; 74(6): 438-44.

40. Schonberger RJ. Reconstituting lean in healthcare: From waste elimination toward 'queue-less' patient-focused care. Bus Horiz 2018; 61(1): 13-22.

41. Jenkins A, Eckel SF. Analyzing methods for improved management of workflow in an outpatient pharmacy setting. Am J Health Syst Pharm 2012; 69(11): 966-71. 